\title{
A Case of Blastic Plasmacytoid Dendritic Cell Neoplasm
}

\author{
Teresa Pinto-Almeida, M.D., Iolanda Fernandes, M.D., Madalena Sanches, M.D., \\ Catarina Lau, M.D. ${ }^{1}$, Margarida Lima, Ph.D. ${ }^{1}$, Rosário Alves, M.D., Manuela Selores, M.D. \\ Departments of Dermatology, ${ }^{1}$ Hematology, Centro Hospitalar do Porto-Hospital de Santo António, Porto, Portugal
}

Blastic plasmacytoid dendritic cell neoplasm (BPDCN) is a rare, highly aggressive hematopoietic malignancy that is characterized by cutaneous and bone marrow involvement and leukemic spread, representing $0.7 \%$ of primary cutaneous lymphomas ${ }^{1}$. Formerly known as CD4+/CD56+ hematodermic neoplasm or blastic NK-cell lymphoma ${ }^{2}$, BPDCN is derived from precursors of plasmacytoid dendritic cells and was only recently established as a distinct entity ${ }^{3}$.

A 74-year-old man presented with a 4-month history of asymptomatic cutaneous lesions that initially appeared on his face but progressively spread to his thorax and arms. He had no systemic symptoms. His medical history included peripheral arterial disease and dyslipidemia, for which he was on acenocumarol and rosuvastatin. Physical examination revealed infiltrated violaceous plaques and nodules on his face and thorax and firm subcutaneous nodules on his arms along with reticulated purpuric macules (Fig. 1). Axillary and submandibular lymph nodes were bilaterally palpable. Laboratory data disclosed severe normochromic normocytic anemia (hemoglobin, $4.4 \mathrm{~g} / \mathrm{dl}$ ), thrombocytopenia $\left(53 \times 10^{9} / \mathrm{L}\right)$, leukocytosis $\left(16.48 \times 10^{9} / \mathrm{L}\right)$ with $44 \%$ of morphologically immature atypical cells and elevated $\beta$ 2-microglobulin $(3.8 \mathrm{mg} / \mathrm{L})$. Flow cytometry (FCM) of the skin cells and the peripheral blood showed $35 \%$ and $37 \%$, respectively, of cells with the following immunophenotype (Fig. 2A, B): positive CD45 (dim),

Received July 22, 2011, Revised August 6, 2011, Accepted for publication August 19, 2011

Corresponding author: Teresa Pinto-Almeida, M.D., Department of Dermatology, Edifício das Consultas Externas, Ex. CICAP, Rua D. Manuel II, s/n, 4100 Porto, Portugal. Tel: 351-917802044, Fax: 351-226097429, E-mail: teresap.almeida@hotmail.com

This is an Open Access article distributed under the terms of the Creative Commons Attribution Non-Commercial License (http:// creativecommons.org/licenses/by-nc/3.0) which permits unrestricted non-commercial use, distribution, and reproduction in any medium, provided the original work is properly cited.
CD4, CD56, CD123, CD7 (dim), HLA-DR, and CD38. Other T/NK (CD1a, CD2, CD3, TCR, CD5, CD8, CD16, CD94, CD161), B (CD19, CD20, CD79a), myeloid (CD11b, CD13, CD14, CD15, CD33, CD64, myeloperoxidase) and immature cell (CD34) markers tested negative. Histopathology of a skin lesion showed a monomorphous diffuse infiltrate of large blastic cells with irregular nuclei occupying the entire dermis and infiltrating the subcutaneous tissue (Fig. 2C, D). Immunohistochemical analysis confirmed the presence of cells with the aforementioned immunophenotypic features. No chromosomal alterations were detected by cytogenetic analysis of peripheral blood cells. Computed tomography scans disclosed basal lung consolidation suggestive of malignant infiltration, mediastinal, hilar, axillary and retroperitoneal lymphadenopathy, hepatomegaly, and splenomegaly, findings that were compatible with widespread disease. Bone marrow analysis was not performed once its involvement was confirmed by the altered peripheral blood profile. Together these findings fulfilled the requirements for the diagnosis of BPDCN. The patient started palliative chemotherapy with cytarabine and mitoxantrone but died 3 weeks later of multi-organ failure.

BPDCN is a rapidly evolving disease that primarily affects the elderly. The clinical presentation is quite constant, with $90 \%$ of patients presenting with asymptomatic solitary/ multifocal cutaneous reddish-brown nodules or bruise-like lesions ${ }^{4,5}$. Bone marrow is involved in most cases, and practically any organ can be affected. The disease follows a short course and fulminant leukemia is the common terminal stage ${ }^{4-6}$. The diagnosis relies on the immunophenotypic features of the malignant cells. FCM is preferred over immunohistochemical analysis since it allows for the examination of more markers and their intensity determination ${ }^{7,8}$. The expression of CD4, CD56, and CD123 in the absence of T-cell, B-cell, or myeloid markers defines $\mathrm{BPDCN}^{4-8}$. The correct diagnosis implies an appropriate panel of antibodies; in contrast, insufficient knowledge on 

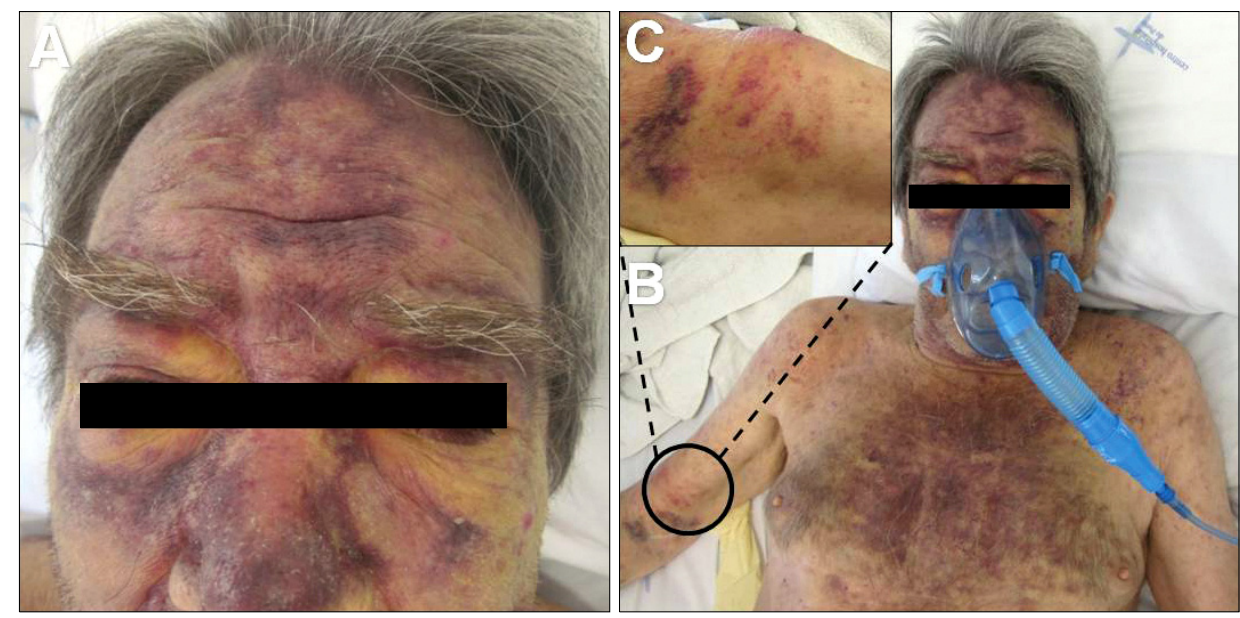

Fig. 1. (A, B) Features of the cutaneous lesions on the face and thorax. (C) Highlight of one firm subcutaneous nodule on the right arm. this entity and inadequate immunophenotypic investigation can lead to the misdiagnosis of a different leukemia ${ }^{8}$. Cytogenetic analysis is not helpful since no recurrent specific chromosomal aberrations were recognized ${ }^{7,8}$. The prognosis of patients with BPDCN is poor, with a median survival of $12 \sim 14$ months regardless of treatment type ${ }^{9}$. Acute lymphoblastic leukemia-type treatment regimens are advised and a promising initial response may occur, but is followed by quick relapse ${ }^{6,9,10}$. Long-term remissions have been rarely reported in younger patients who received acute leukemia-type induction therapy and allogeneic stem cell transplantation ${ }^{9-11}$.

Although clarification of the immunophenotypic features of BPDCN has improved its recognition, this entity remains a diagnostic challenge. Cutaneous lesions are usually the only sign of the disease, so dermatologists should be knowledgeable about it and play a crucial role in uncovering this malignancy and avoiding diagnostic delays.

\section{REFERENCES}

1. Petrella $T$, Bagot $M$, Willemze R, Beylot-Barry $M$, Vergier $B$, Delaunay $M$, et al. Blastic NK-cell lymphomas (agranular CD4 + CD56 + hematodermic neoplasms): a review. Am J Clin Pathol 2005;123:662-675.

2. Willemze R, Jaffe ES, Burg G, Cerroni L, Berti E, Swerdlow $\mathrm{SH}$, et al. WHO-EORTC classification for cutaneous lymphomas. Blood 2005; 105:3768-3785.

3. Faccheti F, Jones DM, Petrella T. Blastic plasmacytoid den- dritic cell neoplasm. In: Swerdlow SH, Campo E, Harris NL, Jaffe ES, Pileri SA, Stein $\mathrm{H}$, et al., editors. WHO classification of tumours of haematopoietic and lymphoid tissues. 4th ed. Lyon: International Agency for Research on Cancer, 2008: 145-147.

4. Whittle AM, Howard MR. Skin lesions in plasmacytoid dendritic cell leukaemia. Br J Haematol 2008;140:121.

5. Magro CM, Porcu P, Schaefer J, Erter JW, Furman RR, Shitabata PK, et al. Cutaneous CD4 + CD56 + hematologic malignancies. J Am Acad Dermatol 2010;63:292-308.

6. Herling $M$, Jones D. CD4+/CD56+ hematodermic tumor: the features of an evolving entity and its relationship to dendritic cells. Am J Clin Pathol 2007;127:687-700.

7. Garnache-Ottou F, Feuillard J, Ferrand C, Biichle S, Trimoreau F, Seilles E, et al. Extended diagnostic criteria for plasmacytoid dendritic cell leukaemia. Br J Haematol 2009; 145:624-636.

8. Tsagarakis NJ, Kentrou NA, Papadimitriou KA, Pagoni $M$, Kokkini G, Papadaki $\mathrm{H}$, et al. Acute lymphoplasmacytoid dendritic cell (DC2) leukemia: results from the Hellenic Dendritic Cell Leukemia Study Group. Leuk Res 2010;34: 438-446.

9. Feuillard J, Jacob MC, Valensi F, Maynadié $M$, Gressin R, Chaperot $L$, et al. Clinical and biologic features of CD4(+) CD56(+) malignancies. Blood 2002;99:1556-1563.

10. Reimer $P$, Rüdiger $T$, Kraemer $D$, Kunzmann $V$, Weissinger $\mathrm{F}$, Zettl A, et al. What is CD4 + CD56+ malignancy and how should it be treated? Bone Marrow Transplant 2003;32: 637-646.

11. Jegalian AG, Buxbaum NP, Facchetti F, Raffeld M, Pittaluga $S$, Wayne AS, et al. Blastic plasmacytoid dendritic cell neoplasm in children: diagnostic features and clinical implications. Haematologica 2010;95:1873-1879. 
A
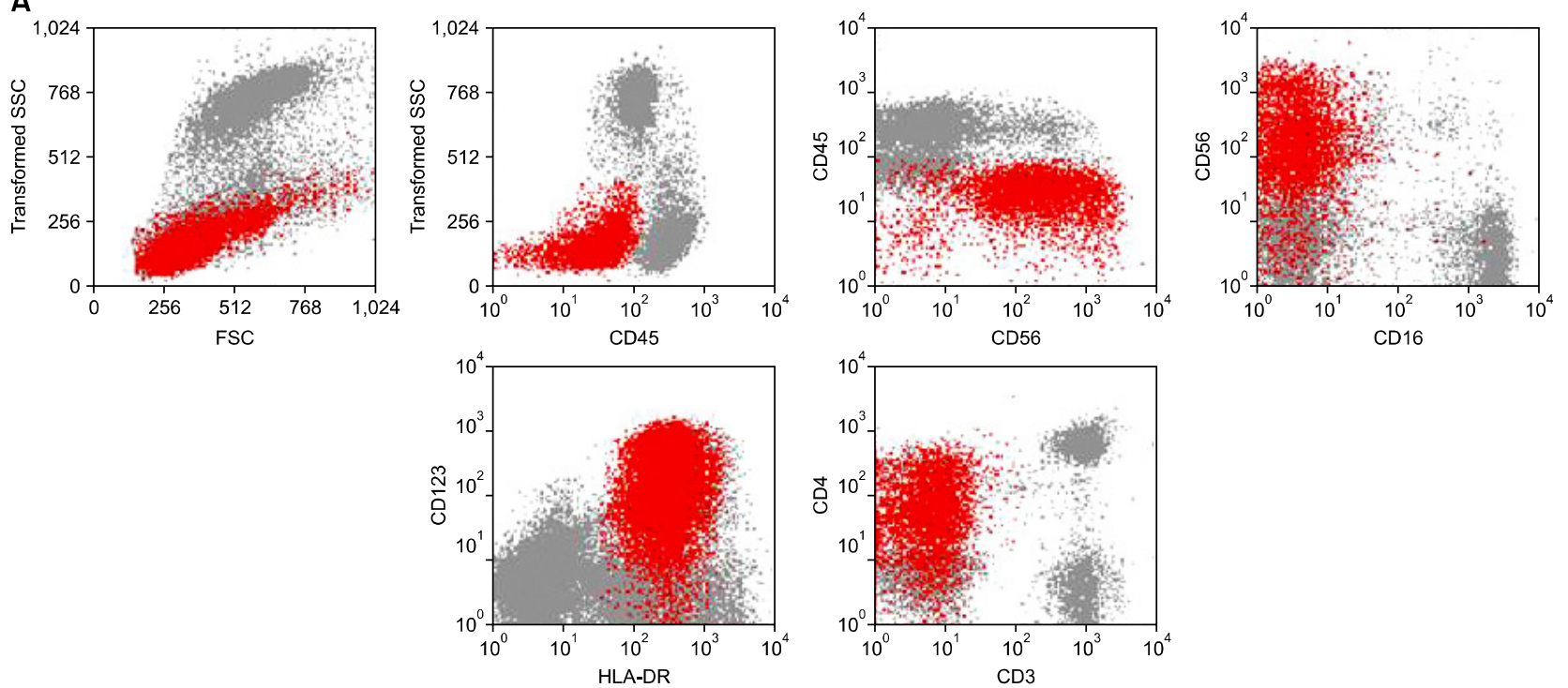

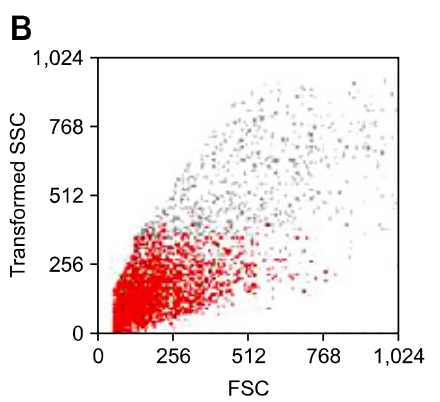

C

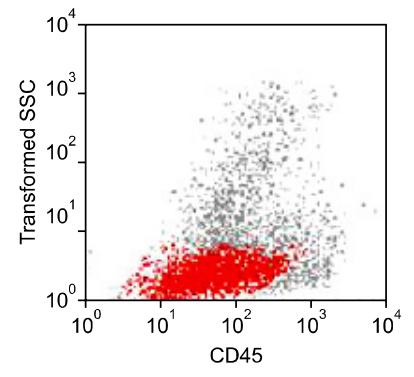

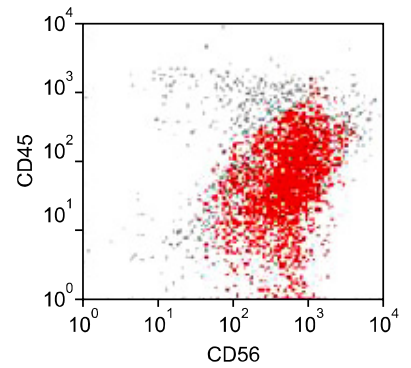

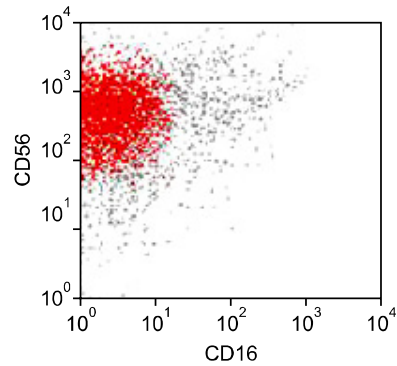

D
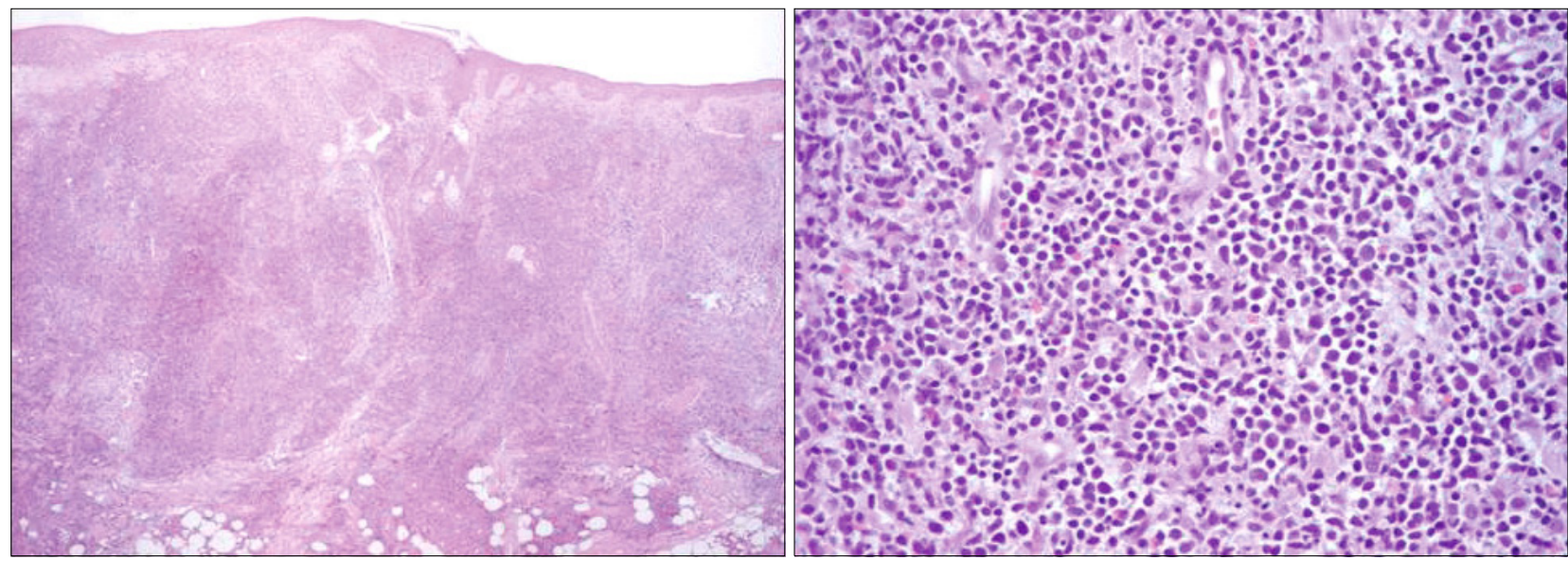

Fig. 2. (A, B) Flow cytometry dot plots of peripheral blood (A) and skin (B) cells showing blastic plasmacytoid dendritic cells (blastic plasmacytoid dendritic cell neoplasm, red dots), respectively, expressing CD45 (dim), CD4 (dim), CD56, CD123, and HLA-DR. (C, D) Histopathological examination of a cutaneous lesion. (C) Diffuse infiltrate occupying the entire dermis and infiltrating the subcutaneous tissue (hematoxylin and eosin stain [H\&E]; original magnification, $\times 4$ ). (D) Higher amplification of the large blastic cells with large irregular nuclei $(\mathrm{H} \& \mathrm{E}$; original magnification, $\times 40)$. SSC: side scatter; FSC: forward scatter. 